\title{
Reseña de Tuan, Yi-Fu. (2015). Geografía romántica. En busca del paisaje sublime (Colección Paisaje y Teoría). Madrid: Biblioteca Nueva.
}

\author{
Jesús Israel BAXIN MARTíNEZ \\ Facultad de Filosofía y Letras, \\ Universidad Nacional Autónoma de MéXico \\ México
}

\section{Presentación}

Yi-Fu Tuan es a la geografía humanista lo que David Harvey a la geografía crítica o Don Mitchell a la geografía cultural estadounidense, más que un referente, un constructor importante de los postulados que han articulado ideas para que otros estudiosos realicen aportes de relevancia. Estos autores han brindado aspectos paradigmáticos para las corrientes de pensamiento y enfoques concretos de la geografía contemporánea. Conocido por los postulados que conceptualizó en la Topofilia, asociación de hechos y recuerdos agradables con los lugares, en esta obra, Yi-Fu Tuan reflexiona sobre el romanticismo en la geografía: "Lo romántico es el impulso de ir más allá de la norma, más allá de lo que es natural y necesario [...]. Lo romántico nunca es sensato" (119). Originalmente publicada en 2013 en Wisconsin, Estados Unidos, la obra se tradujo al español en 2015 por Borja Nogué; la edición y presentación corren a cargo de Joan Nogué como parte de la colección interdisciplinaria de estudios sobre el paisaje de "Biblioteca nueva".

\section{Contribuciones y organización}

La Geografia romántica de Tuan utiliza conceptos musicales para remarcar su prólogo ("Obertura") y epílogo ("Coda") y consta de cuatro capítulos, dos antes de un "interludio" y dos capítulos posteriores. En el primer capítulo, "Valores polarizados", Tuan brinda el marco referencial de su propia filosofía del espacio. Utiliza conceptos binarios como alfombra de entrada a su postura, que, con una gama amplia de referencias que van de la Biblia a la literatura y diversos estudios antropológicos e históricos, podríamos catalogar como una propuesta geográfica de la historia cultural. A diferencia de un estudio más erudito como el de Burke (2006), que navega a partir de la "tradición" 
como término clave, incorporando un análisis contextual más europeo que incluye el cuerpo, los gestos o los modales, la propuesta de Tuan resulta eminentemente más espacial considerando al ser humano tanto en la esfera individual como la social y ejemplifica casos de distintas regiones del mundo más allá del clásico "Occidente".

En el capítulo inicial Tuan plantea cómo la civilización ha otorgado una carga de positividad a elementos básicos, tales como la luz, el orden, la mente, el espíritu o la cultura versus sus opuestos: tinieblas, caos, cuerpo, materia y naturaleza. Tomemos como ejemplo el tercer apartado, "Alto y bajo", en el cual la carga de significado puede asociarse con "superior" o "elevado". Tuan observa que, en los modelos arquitectónicos y sociales de las grandes ciudades, las élites y las sedes corporativas emplazan sus moradas en los centros y los puntos más altos, si bien caben excepciones e inversiones, donde sedes gubernamentales como el Palacio de Buckingham o el Pentágono, por su papel estratégico, no podrían tener forma de rascacielos. En apartados posteriores se revisan conceptos como el cuerpo humano y la casa, donde igualmente se reflexiona sobre la ubicación de sus distintas partes en relación con las ideas de luz, forma y altura. En algún momento se puede rememorar a la Poética del espacio de Bachelard, cuando éste reflexionaba sobre la figura del nido: "el bienestar nos devuelve a la primitividad del refugio. Físicamente el ser que recibe la sensación del refugio se estrecha contra sí mismo, se retira, se acurruca, se oculta, se esconde" (Bachelard, 1965: 125), pero Tuan lo hace desde un sentido menos intimista tomando en cuenta la división de las casas respecto a sus funciones e incluso a la presencia de los géneros. En la idea de la relación "dentro" más femenina y el dominio masculino más allá de las fronteras del hogar, la obra de Sánchez Pérez (1990: 71-110), específicamente en "El ceremonial de los sexos", resulta un complemento relevante a este tipo de análisis. Tuan cierra sus reflexiones teóricas de este apartado aludiendo al estatus social como parte de la jerarquía y al cerebro en contraposición al músculo, señalando que en distintas épocas y culturas resultan ámbitos distanciados con un concepto de por medio: el prestigio.

El segundo capítulo, "La Tierra y sus entornos naturales", resulta una propuesta sorpresiva para conocedores del bagaje espacial. Advierte a los lectores especializados que las y los geógrafos no suelen ser escritores con inclinación poética, más bien descriptiva, por lo que, más que elevar el espíritu, tienden a aterrizarlo. Tuan refiere la relación del planeta Tierra respecto al Sistema Solar haciendo una revisión de la percepción geocéntrica anterior a Copérnico y analizando por qué se tienen aún remanentes de las ideas medievales en el pensamiento moderno. Posteriormente asocia los grandes relieves con su respectiva carga ideológica: las montañas, los océanos, los bosques, los desiertos, el hielo. Para cada una de estas formaciones físicas recurre a las ideas culturales y los antivalores que se les ha asociado la humanidad, desde las palabras puestas en la Biblia hasta las que les otorga comunidad científica. Para los océanos, por ejemplo "fuera del dominio de Dios", se señala cómo la búsqueda de un equilibrio o simetría entre masas llevó a la suposición de un continente austral, que fue refutado hasta el siglo XVIII, antes de que finalmente se estableciera la idea de un hemisferio acuático como respuesta al balance y la armonía (Lois, 2013: 101). 
Los seres humanos en su lucha constante por establecer orden han impregnado su huella en el espacio. De ahí que la disminución del bosque y la expansión del desierto no sean temas únicamente de actualidad, sino dominios sobre los que históricamente han avanzado los asentamientos y se han arraigado ideas, como el desdén hacia la densidad del bosque, pero también el surgimiento de nostalgia hacia la naturaleza primigenia. De la geografía renacentista a la contemporánea, múltiples exploraciones contribuyeron a armar el rompecabezas planetario; en el espíritu del esfuerzo humano que significó el descubrimiento de aquellas piezas faltantes, Tuan subraya el halo de romanticismo. Es el caso de Nansen en el Polo Norte (1895) y Shackleton en la Antártida (1908) a diferencia de exploradores antecesores, destaca el autodescubrimiento relacionado con la añoranza del hogar frente a la más pura gelidez, digna de apreciación.

El tercer capítulo, "La ciudad", está dedicado al análisis de la "domesticación" que los seres humanos hemos realizado sobre el espacio para experimentar lo romántico: trayendo el cielo a la Tierra, rompiendo con los ciclos agrícolas, civilizando el invierno, conquistando la noche. Parte de la escritura de este capítulo proviene de un ensayo de Tuan publicado en 1978, "The City: Its Distance from Nature", revisado con la madurez del octagenario. Mediante los apartados de este capítulo, Tuan alude a ideas de la historia cultural mediante hechos concretos como la evolución de la iluminación nocturna hasta el establecimiento de la electricidad, pasando por la pertinencia de pasajes literarios de autores que ilustran momentos específicos de la vida urbana. Se refiere a "Los bajos fondos" para todo el sistema de alcantarillado que resultó necesario para limpiar la suciedad, pero también el avance del transporte subterráneo como una vía alterna y simultánea al tránsito cotidiano. Tuan vuelve a remitir a la "Luz, literal y figurada" para señalar la importancia de la arquitectura en la parte más sublime de las ciudades, y a "Las tinieblas" para identificar que también se experimentan el crimen, la violencia, la desigualdad y la crisis como parte del escenario urbano.

En el cuarto capítulo, "El ser humano", Tuan justifica que, a pesar de que la geografía tiende a buscar siempre la generalidad grupal, resulta importante analizar el papel de tres figuras románticas arquetípicas - el esteta, el héroe y el santo - relevantes en la indagación naturaleza y cultura. Para el análisis de los estetas, dos esculturas son relevantes del cambio ideológico: la Venus de Willendorg (30 000 a. C.) y la reina Nefertiti (1350 a. C.); como héroes, resultan pertinentes el explorador David Livingstone (mediados del siglo XIX), sin duda una figura clave de la curiosidad y trascendencia sobre la exploración en África; así como el explorador inglés Apsley Cherry-Garrard (1922), cuya actuación contribuyó al cuestionamiento de la superioridad moral de los humanos en el Polo Sur, habitado únicamente por pingüinos. Entre los santos que Tuan rescata en su análisis están San Francisco y Dorothy Day, quienes tenían "sed" de algo más allá de la familia, el trabajo y los placeres, de ahí que destaque su impulso romántico en contextos específicos. 


\section{Reflexiones sobre la obra}

En la Coda o "epílogo", Tuan aterriza gran parte de sus observaciones hacia el romanticismo presente y ausente en la geografía y señala la constante aridez en su lenguaje desde que se institucionalizó la predominancia de la cara científica frente a la facera mística. Asimismo, Tuan indica la paradoja de que, a pesar de dedicarse a lo romántico, percibir a la Tierra como el hogar, la geografía queda lejos de la atracción popular. En ese sentido, en los escritos de geógrafos de otros tiempos y enfoques interesados en la imaginación de los seres mitológicos que habitaban espacios desconocidos pueden hallarse halos de romanticismo que ha perdido la disciplina. En ese sentido, destaca en la escritura de Tuan la riqueza en las referencias literarias y culturales: incorpora oportunamente a autores como Shakespeare, Verne, Orwell, Conrad o Dickens en su propuesta geográfica sobre la historia cultural.

A pesar de que, como se observó anteriormente, Tuan refiere a diversas regiones culturales más allá de las típicamente occidentales — China, Arabia o África—, se echa en falta la incorporación de referencias sobre América Latina, India o las islas del Pacífico Sur para lograr un panorama más global en su análisis. El paisaje como concepto clave está implícito a lo largo de la obra; aunque no se define, el lector puede imaginarlo y divisarlo a partir de las descripciones de los entornos naturales o las ciudades descritas con detalle. La idea del romanticismo como "búsqueda de la elevación espiritual" en el paisaje es posible con esta lectura de Tuan, extendiendo una invitación a incorporar puntos de vista que la modernidad ha diluido en el pensamiento: la lectura renovada del paisaje imaginario y literario es, por lo tanto, un desafío para el estudioso contemporáneo de la geografía.

\section{Referencias bibliográficas}

Bachelard, Gaston. (1965). La poética del espacio. México: Fondo de Cultura Económica.

Burke, Peter. (2006). ¿Qué es la historia cultural? Barcelona: Paidós.

Cherry-Garrard, Apsley. (2008 [1922]). El peor viaje del mundo. Valencia: Zeta Bolsillo.

LoIs, Carla. (2013). "Isla vs. Continente. Un ensayo de historia conceptual". Revista de Geografia Norte Grande, (54), 85-107. http://dx.doi.org/10.4067/S071834022013000100006

SÁnchez Pérez, Francisco (1990). La liturgia del espacio: Casarabonela, un pueblo aljamiado. Madrid: Nerea. 